\title{
Development of specific tests in bike-trials riders and relationship with jumping ability
}

\section{Développement de tests spécifiques chez les trialistes et relation avec les qualités de détente}

\section{Short title: Specific tests in bike-trials riders}

\author{
Authors \\ P-C Thomas* K Miny*B Jidovtseff* \\ Liège University, Department of Sport and Rehabilitation Sciences, Liège, Belgium \\ Allée des sports, 4 \\ 4000 Liège \\ belgique \\ Corresponding author : \\ Boris jidovtseff \\ Phone : 0032/43663894 \\ Email : b.jidovtseff@uliege.be
}

\section{Résumé}

Objectif - L'objectif de cette étude était d'une part de mettre sur pied une batterie de tests de terrain permettant d'évaluer les qualités musculaires et spécifiques des trialistes et d'autre part d'analyser leurs caractères discriminants en comparant les performances des pilotes d'élite avec les pilotes amateurs.

Matériel et méthode - Vingt trialistes d'élite et 13 amateurs concourant dans les catégories " 26 pouces " et " 20 pouces " ont réalisé une batterie de tests comprenant des tests de détente non spécifiques ( $S J, C M J, S L S E$, réactivité) et des tests spécifiques sur vélo (Gap test ; le saut vertical élastique et le temps de maintien sur la roue arrière). L'ensemble des tests étaient réalisés sur le terrain avec du matériel transportable.

Résultats - Les résultats offrent des valeurs de référence pour les tests spécifiques originaux et montrent leurs caractères discriminants. Pour tous les tests, on observe une différence significative $(p<0.001)$ entre les pilotes d'élite et les amateurs. De manière générale, les spécialistes du « 20 pouce » présentent des qualités de détente supérieures aux spécialistes du « 26 pouces ». Les corrélations entre les tests de détente pure et les tests spécifiques vélo (Gap et SVE) apparaissent élevées ( $r>0,7)$.

Conclusion - Les tests de terrain proposés se sont avérés extrêmement discriminants. La qualité de détente verticale apparait comme une qualité indispensable chez le trialiste de haut niveau.

Mots clés - tests de terrain ; détente ; élite : vélo trial : trialiste : myotest ; évaluation 


\begin{abstract}
Aims of the study - The first aim of this study was to set a battery of field tests in order to assess specific muscular function of biketrial riders. The second aim was to investigate the discrimination of these tests by comparing the performance of elite and amateur riders.

Material and method - Twenty ELITE biketrial riders and 13 biketrial amateurs (AMAT) underwent field tests. The battery of field tests consisted in four non specific jumping tests (SJ, CMJ,SBJ and Reactivity) and three original specific tests on the bike (bike gap, side-hop over an elastic and holding time on the back-wheel). All the tests were performed on the field with portable equipment.

Results - The results show that bike specific tests are very discriminant: ELITE riders were significantly superior in each test $(p<0.001)$ The 20in riders seem to have a greater jumping ability in comparison with the 24 in riders. The correlation between the jumping field tests and the bike specific tests is fairly high ( $r>0.7)$.

Conclusion - The field tests as well as the bike specific tests showed to be selective and discriminant for the biketrial rider's. Jumping ability appears to be very important in order to achieve the elite level.
\end{abstract}

Keywords - Filed test ; jumping ; elite athlete ; myotest ; biketrial ; assessement.

\title{
Manuscript
}

\section{Introduction}

Trial biking is a spectacular individual sport where the goal is to overcome all types of obstacles without setting a foot or any other part of the body on the ground or on the obstacle within a limited time. Each fault results in penalty points that are accumulated during all the laps. In competition, there are two categories of bicycles that are distinguished by the size of the frame and the wheels: the 20 inches (20in) and the 26 inches (26in). This sport, which can be described as extreme according to its style of practice, is officially recognized by the Union Cycliste Internationale (UCI) and presents an official ranking. Competitions are held at the national, continental and international levels. Surprisingly, despite this worldwide recognition, there is almost no scientific publication about bike trial. However, scientific research appears to be essential in the process of any sport investigation. It gives a better understanding of specific characteristics of the sport, which leads to the development and the optimization of training methods. To date, only the study by Tarnas et al (2012) [1] has focused on trials by analysing characteristics such as the number of years of training required 
to reach the high level (11 years and older), the age of achieving best results $(24.5 \pm 0.5)$ or the main champions' origins (Spain, France, England, Germany). Such as other sports, performance in bike trials depends primarily on technical skills, but this level of proficiency becomes insufficient at a high level when it comes to overcoming and linking up increasingly difficult obstacles. Physical qualities and their developments then become an important factor in sports performance. Furthermore, it is particularly interesting for any coaches to make available specific tests evaluating and analysing the most decisive actions. In this particular sport, there are many vertical and horizontal jumps, with or without momentum, but also a constant search of balance with specific hopping on the rear wheel. From our practical experience, three specific qualities deserve to be assessed in a bike trial population and specific tests should be developed: one test to measure vertical jump ability; one test to measure the horizontal jump ability and one test to measure the ability to hold the bike on the rear wheel during a standardized displacement. To our knowledge, the only recognized test used in this particular sport is the test of the vertical jump over an elastic for which there is an official world record [2]. However, no scientific document describes the procedure to be followed.

Specific tests are very interesting for coaches because they are generally well correlated with field performance [3-5]. On the other hand, they generally combine both physical and technical qualities. An improvement in performance can be explained by one of these factors or by a combination of both. In this case, it is not possible to determine whether an improvement can be attributed to an increase in technical ability or to an increase in physical fitness. Therefore, it may be interesting to complete athletes' assessment by non-specific tests that focus on the physical components. This approach isolates some of the factors that contribute to performance and provides a better understanding of the technical and physical qualities and weaknesses of an athlete. For years, scientists have compared vertical jumps with and without arms in order to investigate the subjects' ability to use their arms during vertical jumps [6]. Similarly, it would be interesting to compare the jumps with bike and the jumps without bike. The analysis of the results should make possible to obtain an index of optimum use of the bicycle technique, as there is an index of optimum use of arms in vertical jumps.

The main objective of this study is to develop specific and standardized tests assessing three key actions of the sport, namely vertical jump, horizontal jump and rear-wheel endurance. Non-specific jumping tests were also carried out in order to investigate the part of technique 
and the part of jumping ability in the performance. The battery of tests was addressed to both elite and amateur 26 inches (26in) and 20 inches (20in) bicycle riders in order to investigate the influence of the bike and the level of proficiency.

\section{Material and Method}

\section{Subjects:}

Thirty-three riders voluntarily participated in the study and were divided into two groups. The first group (ELITE) was made up of 20 riders ranked between the first and the 20th position in the world championship ranking). Twelve are in the 26in category (ELITE 26) and eight are in the 20in category (ELITE 20). The second group (AMAT) included thirteen amateur riders of regional or national level. Seven compete in category 26in' (AMAT 26) and six in category 20in' (AMAT 20). The characteristics (age, height, weight, training volume, years of experience) of the two groups are presented in Table 1. Only training volume was significantly different between the groups.

Table 1: Descriptive data (mean \pm standard deviation) for the ELITES and AMAT riders. Number (n), age, height, weight, training volume (TV), years of practice (YP). Statistical differences between group: * $p<0.001)$

\begin{tabular}{lllllll}
\hline & $\mathbf{n}$ & Age (years) & Height $(\mathbf{m})$ & Weight $(\mathbf{k g})$ & TV (h/week) & YP (years of practice) \\
\hline ELITE & 20 & $22,9 \pm 4,2$ & $1,79 \pm 0,05$ & $76 \pm 6$ & $16 \pm 5,2 *$ & $13 \pm 3,7$ \\
\hline AMAT & 13 & $25 \pm 6,9$ & $1,82 \pm 0,07$ & $76,9 \pm 11$ & $5,6 \pm 2,2$ & $11 \pm 6,7$ \\
\hline
\end{tabular}

\section{Procedures:}

All tests were carried out under field conditions. The riders of the ELITE group were evaluated during three world cup rounds (season 2015) while riders of the AMAT group were evaluated at their training spot. Each of them performed the tests on his own racing bike in light sport clothing (shoes, shorts and t-shirt). All tests were conducted on a hard and flat surface. For each test, participants were asked to give the best of themselves. The test session, which lasted between 60 and 70 minutes per rider, consisted in four non-specific jump tests followed by three specific tests on the trial bike.

Before carrying out the tests, the rider warmed up freely on his competition bike for 10 minutes. Then, he did 3 sets of 20 steppings with increasing intensity. The last set of stepping was performed at maximum intensity. After the warm-up, the riders realized the tests in a standardized order. 
The four jumping tests were squat jump (SJ), counter-movement jump (CMJ), reactivity test (REA) and standing broad jump (SBJ). A portable accelerometer (Myotest Pro, Switzerland) was positioned at the hip level in order to measure the jump height, reactivity index and ground contact time. A tape measure is used to measure the performance of the SBJ. Before starting the measurements, the riders were familiarized with testing procedure in order to ensure the correct understanding of the instructions and maximum performance. Once ready, each driver performed three attempts. The best performance was selected for the analysis. The $\mathrm{SJ}$ is a vertical jump achieved with hands on the hips and initiated from a knee flexion of $90^{\circ}$ without any counter-movement. SJ is representative of the concentric power of the lower limbs. The flexion of the knees was standardized using adjustable elastic that was positioned in the starting position. Each participant was visually observed during the squat jump to ensure that no countermovement was undertaken. The CMJ involved the riders lowering themselves from an initial standing position to a self-selected squat position, followed immediately by a vertical jump. It measures vertical jump using the stretch-shortening cycle. Participants were encouraged at each attempt to jump as high as possible, For the SJ and the $\mathrm{CMJ}$, the athlete was asked to land with completely extended legs in order to minimize the overestimation of the performance $[7,8]$. The REA consists in six repeated vertical jumps. The riders were instructed to jump as high as possible and while reducing ground contact time and knee flexion as much as possible. Jump height (REA-H), ground contact time (REAL-T) and the reactivity index (REA-I) that corresponds to the ratio between the flying time and the ground contact time were kept for analysis. The SBJ is a test in which the rider tries to jump as far as possible from a standing position. It allows to evaluate the horizontal jumping capacity. All broad jump trials were performed along a steel measuring tape, which was fixed to the floor. Subjects began the broad jump with their toes on a marked line fixed at the $0-\mathrm{cm}$ mark of the tape. The distance from the rearmost heel strike to the starting line was marked and measured. The athletes were allowed to use theirs arms to perform the SBJ.

The three specific tests are the bike gap jump (BGJ), the vertical bike jump (VBJ) and the back-wheel holding (BWH). The BGJ is a balanced horizontal jump on the rear wheel executed between two pallets with standardized dimensions (Europallets: $1200 \times 800 \times 144$ $\mathrm{mm}$ ) (figure 1). The rider is positioned with the rear wheel near the edge of the first pallet, performs a forward impulsion and lands rear wheel on the second pallet while maintaining balance. The test cannot be validated if the back-wheel falls back before the pallet and/or touches the ground or when the rider fails to maintain balance after the landing. The initial 
distance between the two pallets was selected according to the level of performance demonstrated by the rider during the familiarization. It was increased by 3,5 or 10 centimeters depending on the difficulty demonstrated during the previous test. At each distance, the rider received a maximum of three attempts. The greatest distance covered successfully was used for the analysis.
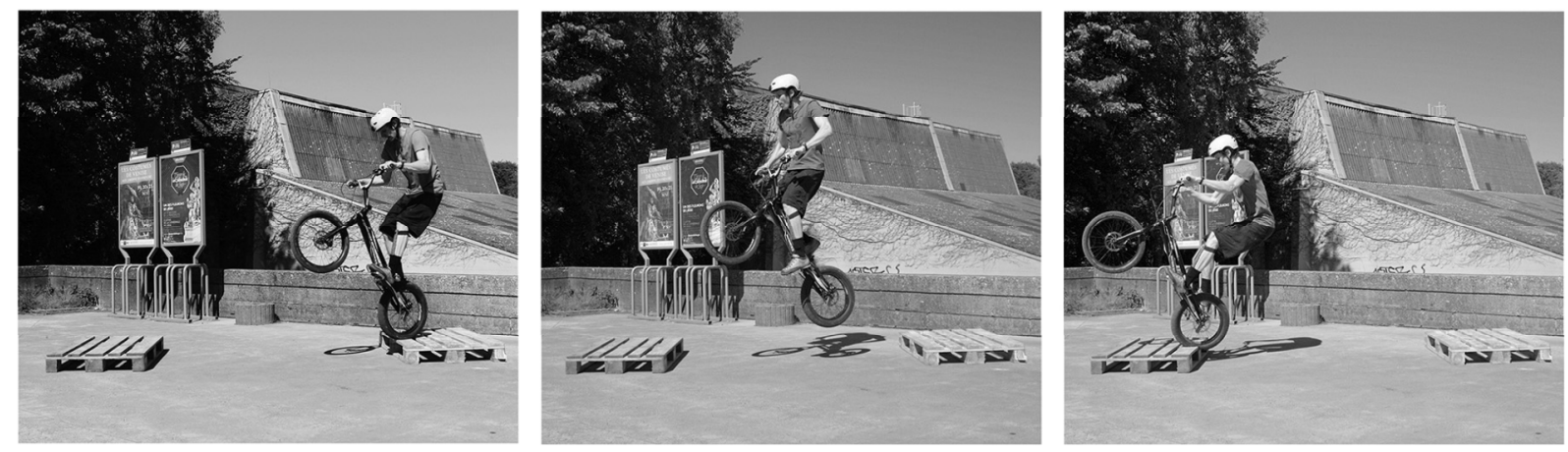

Figure 1 Bike gap jump (BGJ).

The VBJ consists in jumping laterally over an elastic (figure 2). The rider started from a balanced position on the back-wheel and jumped vertically and slightly laterally with his bike over an elastic. The initial height was selected according to the level of performance demonstrated by the athlete during the familiarization. The elastic height was increased by 1 , 3 or 5 centimeters according to the difficulty demonstrated by the subject. At each height, the pilot had a maximum of three attempts. A test was validated when the subject jumped over the elastic without touching it. Landing does not matter in this test. The recorded value was the maximum height passed without touching the elastic.

The BWH was the last specific bicycle test and was performed at the end of the session because of its exhaustive character that could be detrimental to other tests. Two Europallets were positioned upside down at an accurate standardized distance of $50 \mathrm{~cm}$. The aim of the rider is to last as long as possible on the back-wheel while passing from

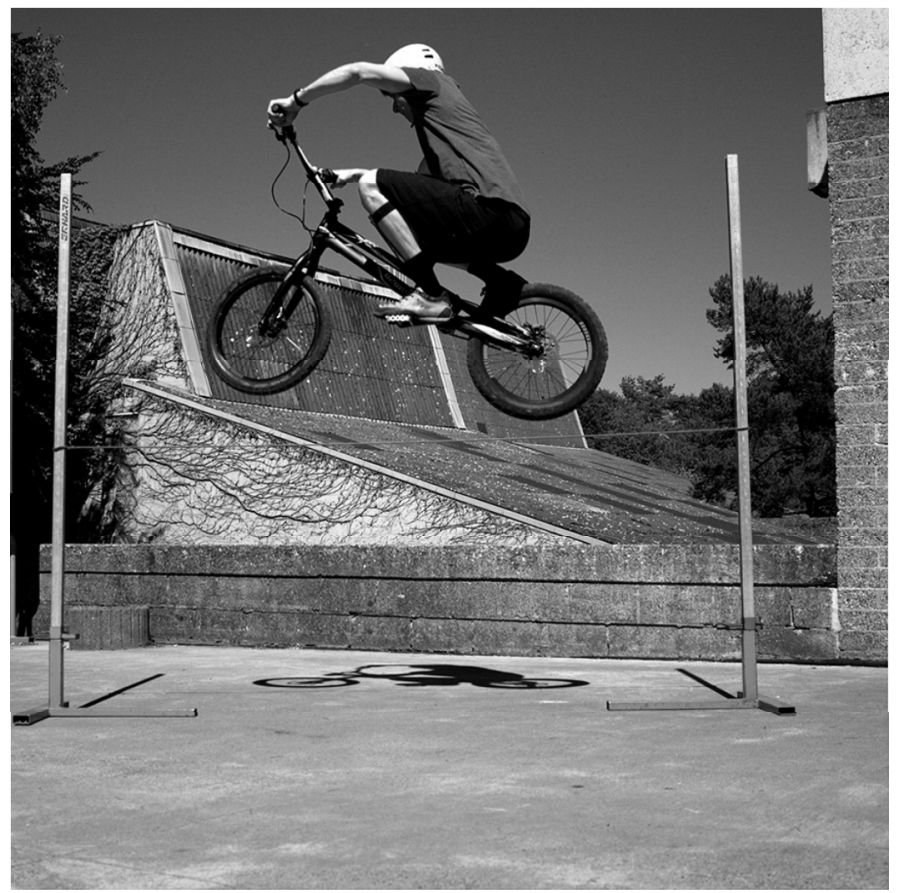

Figure 2 Vertical bike jump (VBJ) [2]. 
one pallet to the other (figure. 3). The pilot starts in front of the first pallet on the back-wheel, moves towards the second pallet by hopping, then makes a jump to reach the second pallet and cross it before going down to the ground. Without putting his foot on the ground, the pilot has to turn back and moves in the opposite direction. The test continues until the front wheel touches the ground. The measured value is the time held on the back-wheel in seconds. This test is quite complete because it integrates the control of the bike, the ability to hop and the specific endurance of the upper-body. All pilots were familiarized with the test before they started their unique attempt. They were instructed to complete the exercise until exhaustion.
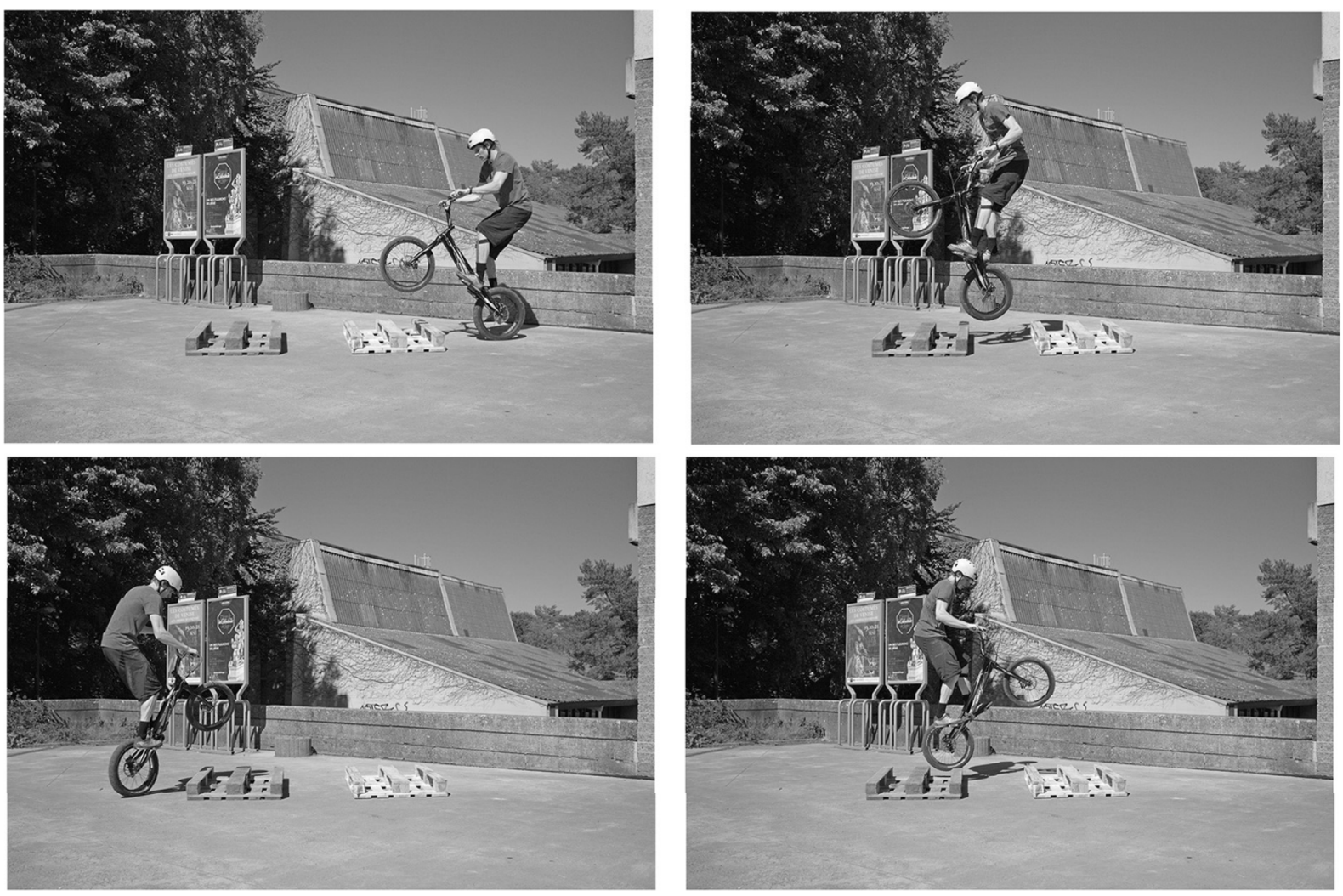

Figure 3 Back wheel holding (BWH).

\section{Statistical analysis:}

Statistical analysis was carried out using the Statistica 12 software (StatSoft, France). The Shapiro-Wilk's test demonstrated the normality of the variables allowing the use of the parametric tests. Descriptive statistics are based on mean and standard deviation. A multivariate analysis of the variance (MANOVA) was used to investigate the effect of the group (AMAT versus ELITE), the effect of the bike (20in versus 26in) and the cross effect group x bike. The Bravais-Pearson correlation coefficients were calculated to analyse the relationships between the different variables measured. Using the classification described by Hopkins (2002), the coefficient is described as: trivial (0.0-0.1), low (0.1-0.3), moderate (0.3- 
0.5), large (0.5-0.7) high (0.7-0.9) and almost perfect (0.9-1). An original vertical technical index (ITV) was calculated and consists in the ratio between the VBJ and the CMJ. A horizontal technical index (ITH) is calculated by making the ratio between BG and SLSE. The total technical index (ITT) is calculated by summing these two indexes $($ ITT $=$ ITV + ITH) and provides an overview of optimum use of the bicycle technique, against the jumping qualities evaluated by the non-specific tests. A level (LEV) parameter was calculated in the ELITE group by taking the 3 best results obtained during the 5 rounds of the 2014-2015 World Cup season. This parameter provides the relations between the performances in the different tests and the level of performance of the ELITE trials rider.

\section{Results}

Descriptive data are presented in the Table 2. The ANOVA shows superior performances of the ELITE group in comparison with the AMAT group for all the tests and parameters. A significant bike effect is reported for the jumping tests (SJ, CMJ, SBJ), REA-I, VBJ, and also for the ITV and ITT. The results shows a significant group x bike effect for BGJ, VBJ and for the three technical indexes.

Table 3 : Correlative analysis : SJ, CMJ, SBJ, REA-H (reactivity height), REA-T (reactivity time), REA-I (reactivity Index), BG (bike gap), VBJ (vertical bike jump), BWH (back wheel holding), W (weight), $H$ (height), TV (training volume), YP (years of practice), $n$ (number), ITT (total technical index), ITH (horizontal technical index), ITV (vertical technical index). All correlation are including all pilots $(N=33)$ except for LEV* were only ELITE pilot were included.

\begin{tabular}{|c|c|c|c|c|c|c|c|c|c|c|c|c|c|c|c|c|}
\hline & SJ & CMJ & SBJ & REA-H & REA-T & REA-I & BGJ & VBJ & BWH & $\mathbf{W}$ & H & TV & VTI & HTI & TTI & YP \\
\hline LEV $^{*}$ & 0,52 & 0,53 & 0,22 & 0,01 & 0,29 & $-0,23$ & 0,55 & 0,66 & 0,12 & 0,48 & 0,13 & 0,49 & 0,11 & 0,20 & 0,32 & 0,15 \\
\hline SJ & 1,00 & 0,89 & 0,80 & 0,61 & $-0,12$ & 0,43 & 0,68 & 0,76 & 0,40 & 0,12 & $-0,09$ & 0,54 & 0.35 & 0.43 & 0.38 & 0,26 \\
\hline CMJ & & 1,00 & 0,79 & 0,68 & $-0,17$ & 0,50 & 0,78 & 0,81 & 0,45 & 0,17 & $-0,22$ & 0,60 & 0.31 & 0.56 & 0.38 & 0,25 \\
\hline SBJ & & & 1,00 & 0,55 & $-0,37$ & 0,53 & 0,75 & 0,73 & 0,44 & 0,16 & $-0,01$ & 0,69 & 0.39 & 0.38 & 0.40 & 0,24 \\
\hline REA-H & & & & 1,00 & $-0,14$ & 0,69 & 0,46 & 0,50 & 0,31 & 0,05 & $-0,17$ & 0,40 & 0.13 & 0.26 & 0.17 & $-0,11$ \\
\hline REA-T & & & & & 1,00 & $-0,77$ & $-0,34$ & $-0,23$ & $-0,28$ & 0,27 & 0,26 & $-0,21$ & -0.24 & -0.24 & -0.25 & $-0,15$ \\
\hline REA-I & & & & & & 1,00 & 0,44 & 0,42 & 0,30 & $-0,20$ & $-0,33$ & 0,35 & 0.19 & 0.27 & 0.21 & 0,03 \\
\hline BGJ & & & & & & & 1,00 & 0,95 & 0,57 & 0,09 & $-0,11$ & 0,64 & 0.74 & 0.9 & 0.81 & 0,48 \\
\hline VBJ & & & & & & & & 1,00 & 0,54 & 0,03 & $-0,14$ & 0,58 & 0.8 & 0.85 & 0.84 & 0,58 \\
\hline BWH & & & & & & & & & 1,00 & $-0,02$ & $-0,16$ & 0,47 & 0.4 & 0.49 & 0.44 & 0,27 \\
\hline W & & & & & & & & & & 1,00 & 0,64 & 0,20 & -0.19 & -0.01 & -0.15 & $-0,11$ \\
\hline $\mathbf{H}$ & & & & & & & & & & & 1,00 & 0,00 & -0.02 & -0.14 & -0.05 & $-0,12$ \\
\hline TV & & & & & & & & & & & & 1,00 & 0.29 & 0.41 & 0.33 & 0,14 \\
\hline VTI & & & & & & & & & & & & & 1.00 & 0.8 & 0.99 & 0.67 \\
\hline HTI & & & & & & & & & & & & & & 1.00 & 0.88 & 0.53 \\
\hline TTI & & & & & & & & & & & & & & & 1.00 & 0.66 \\
\hline YP & & & & & & & & & & & & & & & & 1,00 \\
\hline
\end{tabular}

The correlative analysis in Table 3 reveals almost perfect relations between the BGJ and VBJ tests $(r=0.95)$. Very high relationships are also found between Jump tests (SJ, CMJ and SBJ) 
are highly correlated together and with BGJ and VBJ. The various technical indexes (ITV, ITH, ITT) presents high to very high correlations together and with BGJ and VBJ. All technical indexes shows large correlations with YP. The BWH test presents high correlations only with the other two specific tests. Morphological parameters, on the other hand, are not correlated with any test. High correlations are observed between TV and nonspecific jump tests (SJ, CMJ, SBJ) and specific bike (BGJ and VBJ) tests. Within the ELITE group, the test that appears most related to the level of performance (LEV) is the VBJ test $(r=0.66)$.

Table 2 : Descriptive data (mean \pm standard deviation [extreme values]) and ANOVA analysis (Group effet, Bike effet and group*bike effect) for all measures parameters and index.

\begin{tabular}{|c|c|c|c|c|c|c|}
\hline & & ELITE & AMAT & $\begin{array}{l}\text { Group } \\
\text { effect }\end{array}$ & $\begin{array}{c}\text { Bike } \\
\text { effect }\end{array}$ & $\begin{array}{c}\text { Group*bike } \\
\text { effect }\end{array}$ \\
\hline \multirow[t]{3}{*}{ SJ (m) } & $26^{\prime \prime}$ & $0.41 \pm 0.03[0.36-0.46]$ & $0,33 \pm 0,04$ [28.2-39.1] & & $p<0,01$ & NS \\
\hline & $20^{\prime \prime}$ & $0.45 \pm 0.05$ [0.39-0.53] & $0.38 \pm 0.03[33.2-42]$ & & & \\
\hline & $20+26^{\prime \prime}$ & $0.43 \pm 0.04[0.36-0.53]$ & $0.35 \pm 0.04[28.2-42]$ & $p<0,001$ & & \\
\hline \multirow[t]{3}{*}{ CMJ (m) } & $26^{\prime \prime}$ & $0.46 \pm 0.03[0.41-0.50]$ & $0.36 \pm 0.044[31.5-44.1]$ & & $p<0,05$ & NS \\
\hline & 20 & $0.50 \pm 0.03[0.48-0.54]$ & $0.38 \pm 0.05[29.4-44.9]$ & & & \\
\hline & 20 et 26 & $0.48 \pm 0.04[0.41-0.54]$ & $0.37 \pm 0.05$ [29.4-44.9] & $p<0,001$ & & \\
\hline \multirow[t]{3}{*}{ SBJ (m) } & 26 & $2.65 \pm 0.13[2.45-2.90]$ & $2.26 \pm 0.15$ [206-256] & & $p<0,05$ & NS \\
\hline & 20 & $2.75 \pm 0.17[2.55-3.00]$ & $2.41 \pm 0.16$ [224-262] & & & \\
\hline & 20 et 26 & $2.68 \pm 0.15[2.45-3.00]$ & $2.33 \pm 0.16[206-262]$ & $p<0,001$ & & \\
\hline \multirow{3}{*}{$\begin{array}{l}\text { REA-H } \\
\text { (m) }\end{array}$} & 26 & $0.33 \pm 0.06[0.22-0.43]$ & $0.25 \pm 0.03$ [19.8-27.8] & & NS & NS \\
\hline & 20 & $0.35 \pm 0.05[0.30-0.41]$ & $0.26 \pm 0.05[20.5-31.5]$ & & & \\
\hline & 20 et 26 & $0.33 \pm 0.06[0.22-0.43]$ & $0.25 \pm 0.04[19.8-31.5]$ & $p<0,001$ & & \\
\hline \multirow[t]{3}{*}{ REA-I } & 26 & $4,07 \pm 0,7 \quad[3.29-5.82]$ & $3,14 \pm 0,48[2.72-4.05]$ & & $p<0,05$ & NS \\
\hline & 20 & $4,1 \pm 0,6 \quad[3.43-5.16]$ & $3,29 \pm 0,45$ [2.57-3.94] & & & \\
\hline & 20 et 26 & $4,08 \pm 0,65[3.29-5.82]$ & $3,21 \pm 0,45[2.57-4.05]$ & $p<0,001$ & & \\
\hline \multirow{3}{*}{$\begin{array}{l}\text { REA-T } \\
\text { (ms) }\end{array}$} & 26 & $128,08 \pm 14,37$ [104-149] & $143,14 \pm 16,17[118-166]$ & & NS & NS \\
\hline & 20 & $131,71 \pm 13,72$ [107-147] & $142,83 \pm 25,83[110-177]$ & & & \\
\hline & 20 et 26 & $129,42 \pm 13,86$ [104-149] & $143 \pm 20,22[110-177]$ & $p<0,05$ & & \\
\hline \multirow{3}{*}{$\begin{array}{l}\text { BGJ } \\
(\mathrm{m})\end{array}$} & 26 & $2.96 \pm 0.20[2.55-3.22]$ & $2.00 \pm 0.51[103-260]$ & & NS & $p<0,1$ \\
\hline & 20 & $2.88 \pm 0.17$ [2.60-3.15] & $2.35 \pm 0.23[200-250]$ & & & \\
\hline & 20 et 26 & $2.93 \pm 0.19$ [2.55-3.22] & $2.16 \pm 0.43$ [103-260] & $p<0,001$ & & \\
\hline \multirow{3}{*}{$\begin{array}{l}\text { VBJ } \\
\text { (m) }\end{array}$} & 26 & $1.25 \pm 0.09$ [1.10-1.38] & $0.73 \pm 0.29[20-110]$ & & $p<0,01$ & $p<0,05$ \\
\hline & 20 & $1.30 \pm 0.07$ [1.20-1.40] & $1.05 \pm 0.12[90-125]$ & & & \\
\hline & 20 et 26 & $1.27 \pm 0.09$ [1.10-1.40] & $0.88 \pm 0.26[20-125]$ & $p<0,001$ & & \\
\hline \multirow{3}{*}{$\begin{array}{l}\text { BWH } \\
\text { (s) }\end{array}$} & 26 & $88,4 \pm 28,73[54-135]$ & $33,14 \pm 15,04[6-56]$ & & NS & NS \\
\hline & 20 & $109,86 \pm 73,27[52-240]$ & $42,17 \pm 18,64[23-60]$ & & & \\
\hline & 20 et 26 & $96,32 \pm 49,06[52-240]$ & $37,03 \pm 16,73[6-60]$ & $p<0,001$ & & \\
\hline \multirow[t]{3}{*}{ VTI } & 26 & $2.71 \pm 0.15[2.49-2.97]$ & $1.99 \pm 0.72[0.63-2.68]$ & & $p<0,05$ & $p<0,01$ \\
\hline & 20 & $2.61 \pm 0.21[2.31-2.92]$ & $2.74 \pm 0.28[2.30-3.06]$ & & & \\
\hline & 20 et 26 & $2.67 \pm 0.18$ [2.31-2.97] & $2.34 \pm 0.67[0.63-3.06]$ & $p<0,05$ & & \\
\hline \multirow[t]{3}{*}{ HTI } & 26 & $1.12 \pm 0.08$ [0.99-1.25] & $0.88 \pm 0.21[0.46-1.02]$ & & NS & $p<0,1$ \\
\hline & 20 & $1.06 \pm 0.09[0.95-1.24]$ & $0.98 \pm 0.09$ [0.88-1.12] & & & \\
\hline & 20 et 26 & $1.10 \pm 0.08[0.95-1.25]$ & $0.93 \pm 0.16[0.46-1.12]$ & $p<0,01$ & & \\
\hline \multirow[t]{3}{*}{ TTI } & 26 & $3.83 \pm 0.20[3.61-4.22]$ & $2.87 \pm 0.92[1.10-3.68]$ & & $p<0,1$ & $p<0,01$ \\
\hline & 20 & $3.66 \pm 0.27[3.33-4.16]$ & $3.72 \pm 0.30$ [3.18-3.98] & & & \\
\hline & 20 et 26 & $3.77 \pm 0.24[3.33-4.22]$ & $3.26 \pm 0.81[1.10-3.98]$ & $p<0,05$ & & \\
\hline
\end{tabular}




\section{Discussion}

The main objective of this study was to develop an original battery of field-tests evaluating specific key actions of bike trial. Some empirical field-tests with the bike are often used by the riders as part of their training. However, they haven't been clearly described in the literature and are not necessarily performed with identical procedure from one athlete to another. To the knowledge of the authors, the present study is the very first one to describe such standardized procedure for specific test inspired from our field experience and adapted to bike trial. In rigorous training and/or scientific context, the tests must be well described in order to be reproduced identically wherever it is carried out. One objective was to build tests that required inexpensive, accessible and portable equipment, which was the case with the requirement of just two standardized Europalettes, two vertical sticks and one elastic. It was important that the selected tests evaluate the discriminating and determining actions of bike trial. In this particular sport, the ability to jump high and far away with the bike is very important as it increases the capacity to pass over discriminant obstacles. We decided to isolate horizontal and vertical types of impulsion as the technical approach is not exactly the same. The VBJ is regularly used on the field to determine the athlete's ability to jump vertically as high as possible and there is an official world record [2]. This easy set up test was chosen because it has the reputation of being discriminating in terms of vertical ability to jump on the bike, but has not yet been accurately described in the literature. The BGJ is also an empiric test which is commonly used at training to improve the technique, get used to jump longer distances without risk of falling or to point out the level and the progress. While there is no official world record, many videos showcase the world's best riders attempting to cross the highest possible distance between two obstacles of the same height. This test is ideal for evaluating horizontal jumping power on bicycles. The use of Europallets with standardized dimensions that are regularly used by trialists in training make this test very accessible and easy to organize.

The last specific test (BWH) incorporates the ability of the subject to ride the bike on the rear wheel for a long time. This exhausting test is quite complete as lower limb are involved in the hopping and isometric contraction of the forearms, arms and back are useful to keep the dynamic balance on the bike that is essential for performance in bike trial. In order to be as specific as possible to the reality of the competition, it was important that the trialist was constantly moving on the rear wheel. For this reason, the two Europallets were returned, forcing the rider to move from one to another. This is a totally original test for which there is 
no reference value. These three specific biketrial tests have so far not been the subject of any scientific study. The present study is the first to focus on the specific assessment of bike trial riders and provides quality descriptive data that could be exploited on the field and in further researches.

The table 2 gives descriptive data and extreme values for both ELITE and AMAT groups, which could be very useful to set the level of a rider. The scores observed for the VBJ in the ELITE group $(1.27 \pm 0.09 \mathrm{~m})$ are high; the best performance in our population was $1,40 \mathrm{~m}$, only $4 \mathrm{~cm}$ under the world record [2], confirming the very high level of the subjects participating in the study. The best rider jumped over three meters in the BGJ and maintained BWH longer than 100 seconds.

Non-specific traditional jump tests were added in the battery in order to investigate the jumping ability of the riders and to compare with other populations. Even if the performance in the vertical jumps is slightly overestimated by the Myotest in comparison with other methods such as force plateforms [7] and Optojump [8], ELITE biketrial riders seems to present good jumping ability with average results $(0.42 \mathrm{~m}$ in $\mathrm{SJ} ; 0.48 \mathrm{~m}$ in $\mathrm{CMJ}$ and $2.68 \mathrm{~m}$ in SBJ) comparable to those observed in sports populations known for explosive power [6,914]. The difference between the SJ and the CMJ can be used to inform about the combined effect of elastic energy and myoelectrical potentiation during vertical jumps [15]. In our ELITE population, the difference reaches an average of $11 \%$, which corresponding to the amount described in other studies [14-16]

The analysis of the results shows a highly significant influence of group for almost all the tests confirming the discriminating character of the selected tests. However, the superiority of the ELITE riders is greater in the specific tests $(+35 \%$ for BGJ, $+45 \%$ for VBJ and $+158 \%$ for $\mathrm{BWH})$ compared to non-specific jumping tests $(+15 \%$ for the SBJ $+22 \%$ for SJ, $+28 \%$ for the $\mathrm{CMJ}$ ), demonstrating that they do not only possess the best physical qualities, but also a better technique on the bike. These results are supported by the three technical indexes that appear statistically superior in the ELITE population compared to the AMAT population. A deep analysis of the results shows, however, that this statement is mainly valid for the 26in riders. Indeed, the amateur population specialized on the 20in bike does not perform as well as the ELITE although they present identical technical indexes. This suggests that their jumping technique on the bike could be equivalent to the high level riders. Interestingly, in 
terms of years of practice, the 20in riders of the AMAT group have an equivalent number compared to ELITE riders (13 \pm 5 years), which is not the case for the 26in pilots of the AMAT group ( $9 \pm 6$ years). The ANOVA study shows an influence of the bike on many parameters. The differences observed can be due to the differences related to the muscular qualities on one hand and on the particularities of each bike on the other hand. From our experience in biketrial, it appears that the 26in riders pass through bigger obstacles in competition. It is important to note that the obstacles appear much less high and intimidating when standing on a 26in bike. However, the 20in drivers systematically and significantly show greater jumping capacity without the bike. The difference is 3.6\% (BJ), 5.4\% (CMJ) and $8.3 \%$ (SJ) in favour of the $20 \mathrm{in}$ riders. The fact that the 20 "s obtain better results in the nonspecific tests seems to show that the jumping capacity is more decisive on a 20in whereas the technical qualities seem to be major for the 26in. This hypothesis seems to be confirmed by a significantly higher TTI in 26in specialists. The best performances observed in the 20in for the VBJ are probably not only explained by a better vertical jump. A bike weight difference of $15 \%$ on average and a bigger and bouncier tire could also play in favour of the $20 \mathrm{in}$. The starting height would be about fifteen centimetres higher on a 26in. This initial advantage, on the other hand, seems to be offset when the elastic is crossed, because at equal height, when the two wheels are above the elastic, the 20in riders' centre of gravity would be lower than the 26 in riders. On the other hand, when the landing occurs on an obstacle, the 26 in would be advantageous. One must be cautious in the interpretation because during the vertical static jump (known as side hop) on an obstacle, some riders often use the front wheel as a support. The technique used for jumping above the elastic does not exactly match the technique used to jump on an obstacle. The jump over the elastic is one of the only techniques benefiting the 20in to jump higher than the 26in. Every world record for the jump over the elastic was accomplished with a 20in. The difference in weight, the more bouncing tire and the greater range of motion is therefore more advantageous than the difference in initial starting height for this specific jump.

There is no significant bike effect for the BGJ test., However, a small superiority of $2.3 \%$ is noted in the 26in ELITES group, suggesting that a bigger bike could give a slight advantage for this technique. The fact that the best performance in our population $(3 \mathrm{~m} 22)$ and the unofficial record ( $3 \mathrm{~m} 34$ by Damon Watson in Spring 2010) were achieved on a 26in bike supports this hypothesis. The advantage, however, appears slight and insignificant. 
The ANOVA analysis shows that there is no significant influence of the bike on the BWH performance, even if the best result was recorded on a 20in bike (240 seconds). This test presents an important variability that could be explained by several aspects. First of all, this endurance test ends at the first mistake. Typically, errors appear more easily with fatigue, but they still can occur before this state of fatigue. Given its exhausting feature, only one attempt can be performed, limiting the chance to obtain the best performance from each rider. The willingness to complete the effort and the ability to push through considering the pain during the effort may be uneven among riders. The psychological factor such as motivation and concentration appear very important in this test. Some riders of the ELITE group realized it the day before a world cup. It is possible that, despite the instructions given to go to exhaustion and the encouragement, some of them did not try hard enough in order to stay fit for the competition. This is a bias that we are aware of, but it was impossible to proceed in any other way to obtain the values of these very high-level riders. Despite these limits, the test BWH remain interesting as it was successful to discriminate ELITE and AMAT riders and offers standardized methods to measure longitudinal improvements in this specific task on the field. The frequent use of BWH in the training context should be interesting for any riders in order to improve this specific ability as well as to receive direct and objective feedback on their progression.

The correlative analysis shows high to very high relationships between the jumping tests and specific bicycle tests except for the BWH. These results were expected as the strategy to jump with a bike are similar to the strategy to jump on the ground. The use of a countermovement on the bike is also very useful in order to jump higher, such as CMJ. It is therefore not surprising that the specific tests are more correlated with CMJ than SJ. Reactivity tests present lower correlations with bicycle tests in comparison with other jumping tests. The ankle reactivity qualities are useful in some aspects of the practice, but are probably not as decisive as the maximum jumping ability. The jumps in trials usually involve knee flexion, which is found in the SJ, CMJ and SBJ tests but is prohibited in the reactivity test.

The BGJ and VBJ tests have almost a perfect correlation $(\mathrm{r}=0.95)$, which demonstrates that these two tests have redundancy, despite the different types of jumping impulsions: horizontal versus vertical. However, if only one of the two tests has to be chosen, VBJ would be preferred since it had a slightly higher correlation with the LEV. This higher correlation could be explained by a possible dominance of vertical jumps (versus horizontal) in sections. As a 
fact, UCI tracers prefer to make vertical obstacles harder because doing so on horizontal obstacles would be much more dangerous and difficult to build. Moreover, from our experience in competitions, a rider will more likely make a difference with obstacles requiring a vertical impulse.

The correlative analysis shows that the ITT is the most interesting technical index because it is strongly correlated with the two specific bike tests and correlated with non-specific jumping tests. On the other hand, there is no correlation between the technical index and the level of the riders. Interestingly, a high correlation $(r=0.67)$ appears between ITT and the number of years of practice, confirming the study of Tarnas [1] according to which the trial is a complex sport requiring a decade of practice to reach the high level.

Interestingly, BGJ and VBJ have moderate to high correlations with level (LEV), which is absolutely not the case with BWH. The world's best trials riders are much better at the jumping tests and the bike tests. The difference between the ELITE group and the AMAT group is $14 \%(\mathrm{BJ}), 18 \%(\mathrm{SJ}), 22 \%(\mathrm{CMJ}), \mathrm{BG}(26 \%)$ and $\mathrm{VBJ}(31 \%)$. The jumping capacity is a fundamental factor in achieving high level in competition. The objective of creating a discriminating battery of tests seems to have been achieved. There is a strong correlation between the best 3 results for the World Cup 2014-2015 (LEV) and the SJ and CMJ performance $(r=0.53)$ and VBJ $(R=0.66)$. These tests seem to be discriminating and it can be said that high-level riders with excellent jumping ability on bike are more likely to perform better in competition.

\section{Conclusion}

The study offers specific and discriminating field tests adapted to biketrial specialists. The VBJ appears particularly interesting and discriminating. The BWH test appears interesting, but reveals a great variability. The analysis of the results shows that high-level riders have excellent jumping qualities. Proper neuromuscular training appears essential for performance. The comparison of the groups shows that the high level requires not only an excellent technique, but also very good physical qualities. The $20 \mathrm{in}$ riders have better jumping capacity without the bike, but a lower technical index compared to the 26 in riders. The overall results of this study should contribute to the improvement of the knowledge on the biketrial and presents substantial information which should allow the optimization of the training of the riders. 


\section{References}

1. Tarnas J, Wieliński D, De La Fuente B, Arguelles J. BIKE TRIAL--CHARACTERISATION OF THE EVENT IN VIEW OF THE UCI WORLD CHAMPIONSHIPS FROM 2003 TO 2011. Stud Phys Cult Tour. 2012;18(4).

2. Glenday C. Guinness world records 2014. Bantam; 2014. 272 p.

3. Carlo C, Manzi V, Impellizzeri F, Weston M, Alvarez JCB. Relationship between endurance field tests and match performance in young soccer players. J Strength Cond Res.

2010;24(12):3227-33.

4. Rampinini E, Bishop D, Marcora SM, Ferrari Bravo D, Sassi R, Impellizzeri FM. Validity of simple field tests as indicators of match-related physical performance in top-level professional soccer players. Int J Sports Med. 2007;28(3):228-35.

5. Carlock JM, Smith SL, Hartman MJ, Morris RT, Ciroslan DA, Pierce KC, et al. The relationship between vertical jump power estimates and weightlifting ability: A field-test approach. J Strength Cond Res. 2004;18(3):534-9.

6. Borràs X, Balius X, Drobnic F, Galilea P. Vertical jump assessment on volleyball: A follow-up of three seasons of a high-level volleyball team. J Strength Cond Res. 2011;25(6):1686-94.

7. Choukou MA, Laffaye G, Taiar R. Reliability and validity of an accele-rometric system for assessing vertical jumping performance. Biol Sport. 2014;31(1):55-62.

8. Casartelli N, Müller R, Maffiuletti NA. Validity and reliability of the Myotest accelerometric system for the assessment of vertical jump height. J Strength Cond Res. 2010;24(11):3186-93.

9. Jidovtseff B, Croisier JL, Mordant B, Crielaard JM. Profil isocinétique des muscles fléchisseurs et extenseurs du genou dans une population d'athlètes sauteurs. Sci Sport. 2005;20(56):304-7.

10. Baker D. Improving Vertical Jump Performance Through General, Special, and Specific Strength Training: A Brief Review. J Strength Cond Res. 1996;10(2):131-6.

11. Balsalobre-Fernández C, Tejero-González CM, Del Campo-Vecino J, Bachero-Mena B, SánchezMartínez J. Relationships among repeated sprint ability, vertical jump performance and upper-body strength in professional basketball players. Arch Med del Deport. 2014;31(161):148-53.

12. Bertucci WM, Hourde C. Laboratory testing and field performance in BMX riders. Vol. 10, Journal of Sports Science and Medicine. 2011. p. 417-9.

13. Papaevangelou E, Metaxas T, Riganas C, Mandroukas A, Vamvakoudis E. Evaluation of soccer performance in professional, semi-professional and amateur players of the same club. J Phys Educ Sport. 2012;12(3):362-70.

14. Komi P V, Bosco C. Utilization of stored elastic energy in leg extensor muscles by men and women. Med Sci Sports. 1978;10(4):261-5.

15. Bosco C, Viitasalo IT, Komi P V, Luhtanen P. Combined effect of elastic energy and myoelectrical potentiation during stretch-shortening cycle exercise. Acta Physiol Scand. 1982;114:557-65.

16. Asmussen E, Bonde-Petersen F. Apparent Efficiency and Storage of Elastic Energy in Human Muscles during Exercise. Acta Physiol Scand. 1974;92(4):537-45. 